\title{
RURAL DEMOCRATIC DESIGN: PARTICIPATORY DESIGN AND SERVICE LEARNING STRATEGIES IN SUSTAINABLE DEVELOPMENT TO PROMOTE CIVIC MINDEDNESS IN COMMUNITY DEVELOPMENT
}

\author{
Julieta TREVINO SHERK ${ }^{1}$ and Carlos COBREROS RODRIGUEZ ${ }^{2}$ \\ ${ }^{1}$ North Carolina State University \\ ${ }^{2}$ Tecnologico de Monterrey, Escuela de Arquitectura, Arte y Diseño
}

\begin{abstract}
The Natural Lab is a design-build programme at the Architecture, Art and Design School at the Tecnologico de Monterrey in Queretaro, Mexico. Ethnographic research and participatory design methods were part of a collaborative process aimed at empowering students in creating a sustainable community for the residents of Tilaco, Mexico. Student teams discovered the real needs of the community through ethnographic research, and were involved in daily activities of the community, the important events, and the festivities. This built deep empathy with the people with whom students were designing, getting to understand who they are, what they do, what they think and feel. The attitude was about understanding the emotional needs of the users. In conjunction with the ethnographic information determined during the discovery phase, students applied participatory design methods throughout the process, beginning with activities that helped community members create a vision for their development. Students adapted participatory methods to all the phases of the design process, which were implemented through community workshops. These workshops helped to address complexities, empower community, and balance the need to preserve natural/cultural resources. The student and community's work culminated in co-design proposals of high social impact through key strategic actions including the construction of small-scale and environmentally responsible projects.
\end{abstract}

Keywords: Service-learning, rural community development, ethnographic studies, participatory design, civic mindedness

\section{INTRODUCTION}

Globally, between 20 and $50 \%$ of the rural population occupies between 95 and $99 \%$ of the territory [19]. Similarly, in Mexico, about 25 million people, 25\% of the country's population, currently live in $98 \%$ of the territory, which shows a very low territorial density [13]. In 1950, the rural population was $57 \%$, and in 1921, it was close to 10 million inhabitants representing $68 \%$ of the total population [13]. The rural territory has large migration flows. Projections made by the National Population Council [5] estimate rural population will decrease from representing $25.1 \%$ in the year 2000 to $21.1 \%$ in 2030 .

Global issues such as population growth, climate change, renewable energies, water resources, and food supply have greatly affected the agricultural, social, cultural, economic, health and environmental status in rural areas. This is where the strongest changes are taking place such as; the most intense concentration of poverty, lack of economic opportunities, shortage of jobs for young people, limited access to information, poor communications and housing, and inadequate health and education services [19]. Design schools and the profession have generally overlooked the rural issue, and few design schools are supporting the rural world in its positive development.

\subsection{Rural Design}

The Natural Lab (NL), a rural design-build programme, worked with the residents of Tilaco, a small 600-member community in Landa de Matamoros, Mexico, in La Sierra Gorda Biosphere Reserve. The NL pedagogy is based on the methodology of Rural Design (RD), a new design/critical thinking method applied to rural problems and opportunities, which apply asset-identification and the problem-solving 
design process to locations in which a "design" strategy was rarely even thought of. In RD, themes can range from agrarian systems and food sovereignty, to land use in the territory, local landscapes and housing, to the different equipment and services that support the rural territory, a territory that provides food for 6,500 million people today and expected to provide 9,000 million with food by 2050 [19]. RD is concerned with the issues that involve the human being in the rural environment and their quality of life. It integrates human and natural systems in a sustainable a design process. It relies on different disciplines to help the communities evolve their view about the spatial configuration of their environment, into a more holistic and systematic point of view, integrating the participatory process in which the community reviews alternative scenarios and multiple solutions [21].

\subsection{Service Learning}

Although there is an abundance of research addressing service learning in general, there is less information about service learning in rural community design. Ash et al. describe the three common components that come together in service learning; academic, relevant service, and critical reflection. Further, they describe the critical reflection goals of service learning in the categories of; personal growth, academic growth, and civic learning [1]. The NL works as a service learning programme, addressing RD as a new way of design thinking, helping to solve challenges from an eco-social innovation position. Like Ash et al. explain, the course integrates all aspects of service learning and uses the design process, which sets the stage for the opportunity for critical student reflection at each stage of the process (Table 1) [1].

The service-learning course involves real-world learning experiences outside the university in the rural environment. It engages students with the participation of rural community members in design/building projects. This living laboratory explores and develops new teaching and learning methods resulting in the students' and the community's enhanced skills. Ethnographic research and participatory design methods were part of teaching this collaborative process aimed at empowering students in promoting sustainable positive development.

\subsection{Ethnographic Research}

The NL understands the importance of teaching students critical thinking as applied to real design problems, which provides the advantage of working with a small community where students can get involved in people's lives, create emotional bonds while integrating into a new social structure, which becomes close and understandable to them. Ethnographic research, as a complex but useful method helps students discover the real needs of people and the community [21,11,4]. It serves as a complement to other types of research [13,4], from the immersion of the researcher in the particular local reality [8], to understanding how people operate in their daily activities[13] observing very particular phenomena[16] specific to each local context.

The behaviour of people is studied with interviews, team discussions, conversations and non-verbal interactions, remaining open to the discovery of novel or unexpected assets and problems from a reflective and empathic position [15]. It encompasses the mundane, the routine, and the non-verbal [3]. What is discovered is intrinsically related to the way it is discovered [11]. In the case of the NL, microethnography was applied, a strategy to focus on a particular aspect in a small period of time [4]. "Tilaquenses" information cards resulted from these interactions, which included participant personal data like trade/work, family information as well as revealing relevant leaders, topics of interest and concerns of the community.

\subsection{Participatory Design}

Designers, with different capacities and abilities, approach participatory design based on the reinvention of his relationship with the user, looking for a closer relationship with the community from a co-creation, more appropriate, effective and adaptable perspective. The designer has a fundamental role in collaborative and interdisciplinary teams that contribute to the design using the creative design process [22]. The NL undertakes the participatory design process as a tool for; inclusion, the expansion of the collective power [12], the improvement of governance structures [7], and for the generation of positive social change. It involves a wide variety of stakeholders to reach the "real" needs [2], applying the use of new information and communication technologies, and facilitating processes of User-Centred Design, generating more responsible results [14]. This results in making a more direct relationship between the technical knowledge of the designer and the user's practical knowledge [17,15]. 
Participatory design becomes a practice of social mobilisation and a response seeking new meanings within social production [9] that lead to the utopian and alternative futures, including diversity, multiplicity and asymmetry between the agents with decision-making power, forming relationships of solidarity, alliance and trust, and including the idea of scale to solve local problems. This provides possibilities of adaptation, replicability, and an open-end that responds to the possibility of generating positive change in a sustainable manner over time [2].

In our study, approximately 50 members of the community (population 600) participated regularly in the design workshops. Students applied participatory design methods beginning with activities that help the community members create a vision for their development. Participatory methods were employed in all phases of the design process in the student-led workshops. Through learning and applying participatory design methods with community, students receive hands-on educational experiences. These workshops help to address complexities, empower the community, and balance the need to preserve natural and cultural resources. The process culminated with a collaborative co-design, which resulted in impactful construction/materialisation projects for the community. The students and community co-designed three projects, which serve the community needs identified through the workshops. The built projects included a community garden and covered workspace, an amphitheatre seating intervention, and an improved entrance/gathering space for the community's library.

\section{METHODS}

The course used the stages of participatory design process, which parallel the critical thinking cycle (Table 1) with unique and customised methods and an intense collaborative process to produce a high level of impact and empowerment for students and the rural community members with whom they work. Ethnographic techniques such as shadowing and one-on-one interviews allow for the development of interactions that establish direct contact with 20 community members. In addition, students trained in participatory design methods, in which they learned and applied community development skills in the form of participatory design workshops using Henry Sanoff's Design Games methodologies [19]. Over the period of two semesters of 15 weeks each, seven community workshops were held. The course learning objectives directly related to the design process and its relationship to the principles of critical thinking. To meet course objectives, students assessed and evaluated information discovered during the multiple workshops with community. They considered alternatives, which they shared with community, received feedback from community, which was, in turn, used to make conclusions about their design proposals and to prepare graphic and oral communication that mirrored community priorities and decisions. Students reflected on process and artefacts during all phases of the iterative design process (Table 1).

Table 1. Design Process and Critical Thinking Cycle Aligned with Reflection at Each Step

\begin{tabular}{|c|c|}
\hline Design Process & Critical Thinking \\
\hline $\begin{array}{c}\text { Discovery, Inventory (Physical, Cultural, } \\
\text { Experiential) }\end{array}$ & Raising questions \\
\hline Analysis, synthesis & Assessing relevant information \\
\hline Programme development & Evaluation, Synthesis and generating ideas \\
\hline Conceptual designs & Consider alternatives \\
\hline Schematic design & Reaching conclusions \\
\hline Design Development & Consider conclusions and Effectively \\
Communicating
\end{tabular}




\subsection{Method of assessment}

This study evaluated the effectiveness of the two-semester, service-learning experience on nine students' perception of their role in rural community development. After receiving approval from the Institutional Review Board at North Carolina State University, ten-question pre and post surveys were administered. Student were asked to describe their perceptions of various aspects of the course and their learning experiences. The survey consisted of questions asking students to rank their response using a five-point Likert scale using 1 as low and 5 as high, and they were asked open-ended critical reflection questions. The surveys were delivered in a face-to-face format. A preliminary statistical analysis was conducted and assessed using Excel analysis tools, which summarised student transformation in the area of learning about the community development design process and skill building (Tables 2-5). In addition, the transformation in student perception in the civic role they will play in their future profession were assessed in the critical reflection's statements, which were evaluated for content.

\section{RESULTS}

The assessments of the survey responses indicate that the course had positive effects on most student's development in the four categories; confidence in engaging with community, sense of connection to community, understanding of their civic responsibility, and understanding the participatory methods used. In the category of "engagement confidence", we found eight students showing an increase, in the "connection to community" there were nine students showing an increase, in "civic responsibility", seven students show an increase, and finally in "use of participatory design methods", seven students show an increase.

Table.2 Confidence in Engaging with Communities within the Desian Process

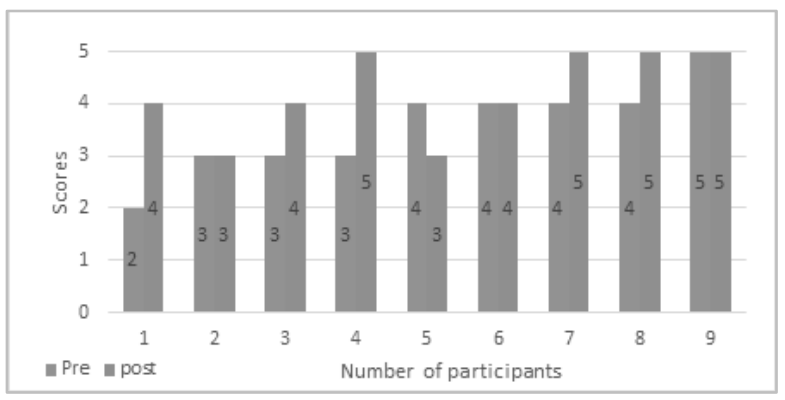

Table 4. Understanding of Professional Civic Responsibility to Community Other

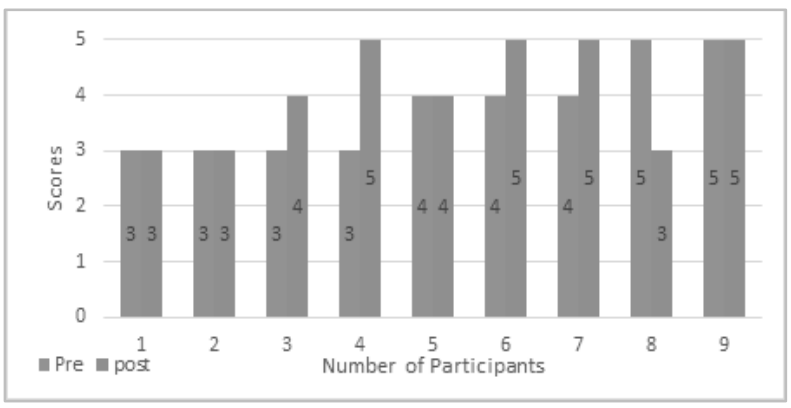

Table 3. Understanding of Sense of Connection with the Community

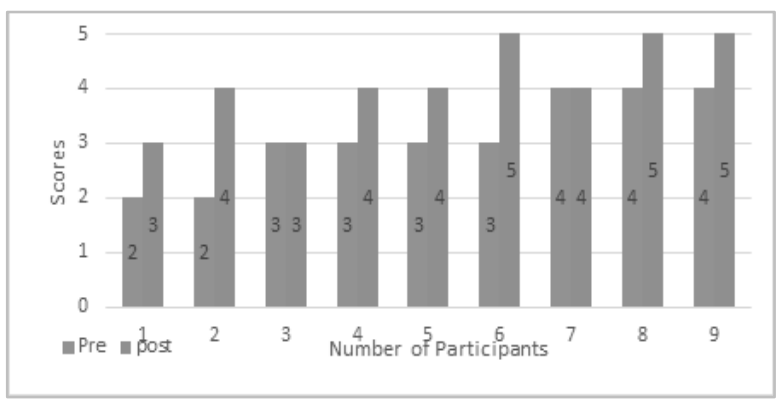

Table 5. Understanding of the Methods used to relate to Real-world Issues

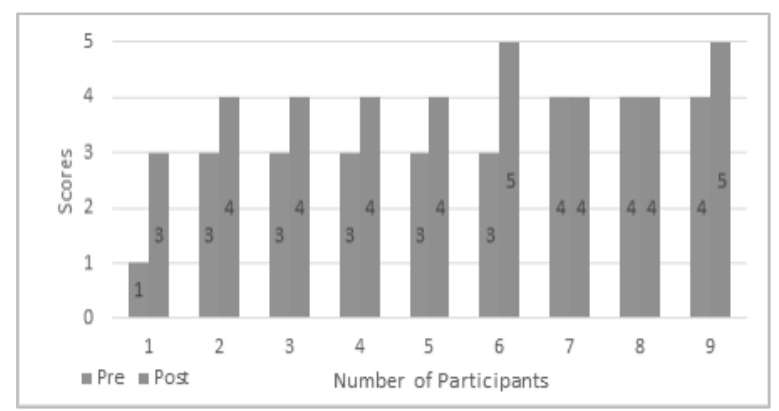

Linguistic measure using a content analysis of student responses indicate student perception toward a more civic oriented role in their future careers as witnessed in comments seen in Figure 1. 


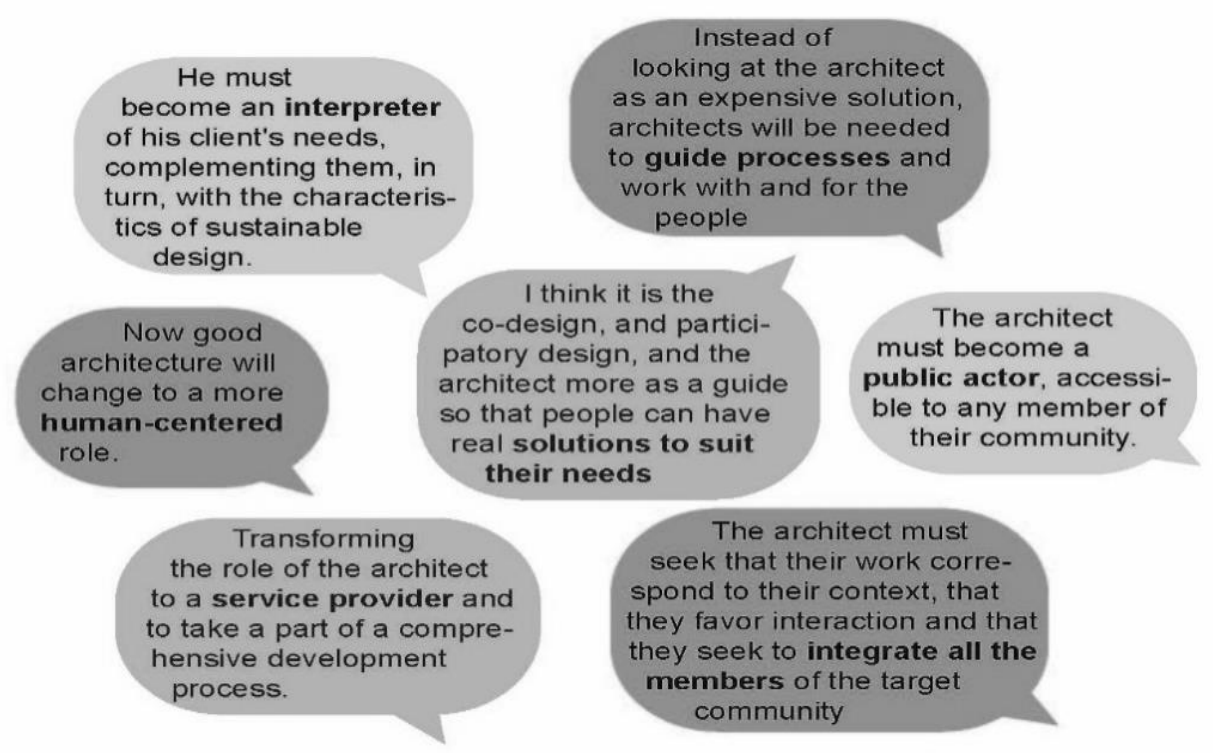

Figure 1. Student Critical Reflection Comments Supporting Civic Mindedness

\section{DISCUSSION/CONCLUSION}

According to the UCLA Leveraging Equity and Access in Democratic Education (LEADE) initiative, civic learning is a process through which students develop the knowledge, skills, and commitments to interact effectively with fellow community members to address shared problems. It includes preparation for both civic and political engagement. Their framework states the core domains of civic learning are civic knowledge, civic associations, and civic action. It also states that the key qualities of learning as information rich, critical and strategic, participatory, culturally responsive, and reflective [6]. Similarly, the learning objectives of our course (stated above) also implement the key qualities of civic learning, which are directly aligned with critical thinking principles. These are essential in promoting civic mindedness in community development. While our ethnographic and participatory design methods were rich in information, strategic, action-based and reflective, our course did not include the study of political institutions, rather it included indirect engagement with the political system.

Our findings indicate that the service learning experience has a positive effect on student's perception of their ability to empower themselves and the rural community with whom they worked. Survey responses indicate our course positively affected most student development in "engagement confidence", "connection to community", "civic responsibility", and "use of participatory design methods", (Table 2,3,4,5). This result reinforces the value of implementing this messy, complex, community design and service-learning teaching/learning experience in rural settings.

According to Gould et al, students who receive effective civic learning are: more likely to vote and discuss politics at home, four times more likely to volunteer and work on community issues, more confident in their ability to speak publicly and communicate with their elected representatives [10]. Correspondingly, student critical reflection responses evaluated for content analysis indicate a student perspective toward a more civic oriented role in their future careers, expressing a more civic oriented perception of the role they will have in the profession using words like interpreter, guide, public actor, service provider. Ash et al. consider the "shifts in perspective and practice" that service learning requires at the heart of the self-directed, lifelong learning as a necessary part of becoming a responsible and effective professionals and citizens. They go on to assert that helping students build their capacity for learning, work, and citizenship is the ultimate goal of service learning [1]. Although more longitudinal studies are necessary, this study shows that the approach of teaching critical/design thinking in the context of rural community development in a service learning context is a part of students' preparation as a civic-minded engaged citizen, and a key to quality, positive community development.

Subsequent to the study presented in this paper, work has continued alongside the community with two more courses, during three additional semesters, with the same dynamics of ethnographic work, participatory design and co-design. The methodologies and design tools continue to be improved and have resulted in the construction of three additional built community projects, and three further projects, which are under construction. 
In order to understand its adaptation to different contexts within the rural, Mexican geography, Rural Design, as a new design methodology, needs to be more deeply explored, and analysed, as well as its implication in the learning process for students and community members. Although this paper demonstrates the relevance in the academic pedagogy, that supports student-learning processes, further assessment of impacts to community is warranted. The evaluation of the impact to the community from this rich collaborative process is not the direct objective of this article; however, because of the two and a half years of work with the community, a separate evaluation will be designed and carried out during summer of 2019. This will reveal more quantifiable impacts to the community partners.

The high level of engagement by the community and the exhibited continuity of the collaborative work with them is evidence that the community's appreciation for this type of shared work has been valued and respected. In addition, as a result of all these efforts, the first "School of Regenerative Design and Rural Innovation" in Tilaco was created to support the continuation of the exploration the Rural Design process and collaborative work between the community and the academy, a tangible impact of this collaborative work.

\section{REFERENCES}

[1] Ash S.L., Clayton P.H., and Moses M.G. Learning Through Critical Reflection: A Tutorial for Service Learning Students (Instructor's Version). 2008. pp. 1-10.

[2] Apsan A. Re-imagining Participatory Design: Reflecting on the ASF-UK Change by Design Methodology, Design Issues 32, 3, 2016: 98-111.

[3] Bevir M. and Rhodes R. Governance stories, Routledge, London, 2006

[4] Bryman A. Social research methods, 3rd ed. Oxford University Press, Oxford, 2008

[5] De Grammont H. Prologo in Ávila, H. Lo urbano-rural, ¿nuevas expresiones territoriales?, Universidad Nacional Autónoma de México, Cuernavaca, 2005

[6] DiGiacomo D., Hogin E., Kahne J., Rogers J. and Bueso L. Leveraging Equity and Access in Democratic Education (LEADE) UCLACenterX. What is Civic Learning. Available: https://centerx.gseis.ucla.edu/wp-content/uploads/2018/01/What-Is-Civic-Learning_-LEADEInitiative.pdf [Accessed 2019,15,02] (2019)

[7] DiSalvo C. Design, Democracy and Agonistic Pluralism, paper presented at Design Research Society Conference, Montreal, July 7-9, 2010.

[8] Emerson R.M., Fretz R.I. and Shaw L.L. Writing ethnographic fieldnotes, 2nd ed. University of Chicago Press, Chicago, 2011

[9] Fainstein, S. The Just City, Cornwell University Press, London, 2000

[10] Gould J., Hall Jamieson K., Levine P., McConnell T. and Smith D.B. eds. Guardian of Democracy: The Civic Mission of Schools. Philadelphia: Lenore Annenberg Institute for Civics of the Annenberg Public Policy Center and the Civic Mission of Schools: Philadelphia, 2011. p. 6.

[11] Hammersley M. and Atkinson P. (2007). Ethnography: principles in practice, Taylor and Francis Ltd., London, 2007

[12] Harvey D. The Right to the City, New Left Review 53, 2008: 23-40

[13] Majoor S. Coping with ambiguity: An urban megaproject ethnography, Progress in Planning 120, 2018: $1-28$

[15] Manzini E. and Rizzo F. Small Projects/Large Changes: Participatory Design as an Open Participated Process, CoDesign 7, no. 3-4, 2011: 199-215

[16] Ronald R. Ethnography and comparative housing research, International Journal of Housing Policy, 11, 4, 2011: 415-437.

[17] Shepherd S.K. and Achterberg C.L. Qualitative research methodology: data collection, analysis, interpretation, and verification. In: Monsen ER, ed. Research: Successful Approaches. Chicago, Ill:American Dietetic Association; 1992:82-88.

[18] Steen M. Human-Centred Design as a Fragile Encounter, Design Issues 28, 1, 2012: 72-80.

[19] Sanoff H. Design Games, 1979. (William Kaufman, Inc.)

[20] Thorbeck D., Rural Design: A New Design Discipline, Routledge, London: 2012

[21] Van Marrewijk, 2001

[22] Wilson S. and Zamberlan L. 2015 Design for an Unknown Future: Amplified Roles for Collaboration, New Design Knowledge and Creativity, Design Issues 31, 2, 2015: 3-15. 